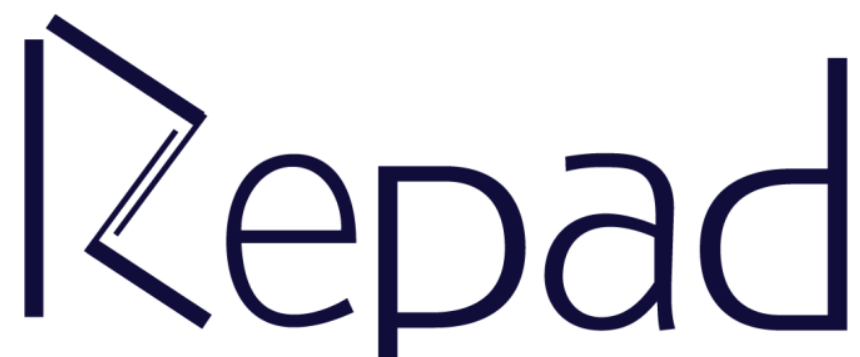

Vol. 2, n 2, AGOSTO//2018

Revista Estudos e

Pesquisas em Administração

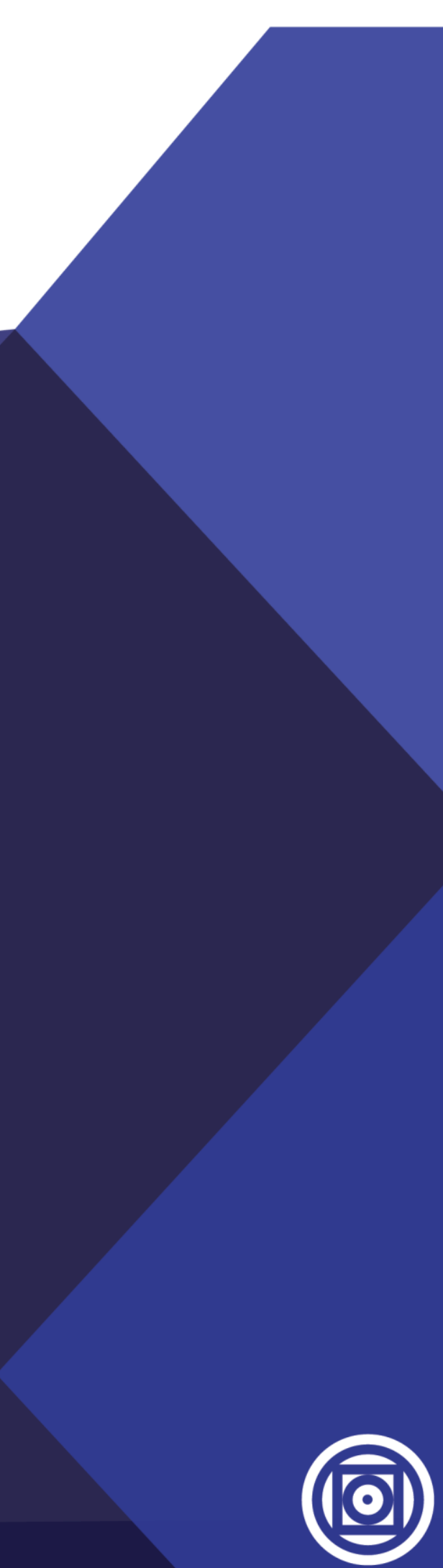




\title{
COMPETENNCIAS DO ADMINISTRADOR DESENVOLVIDAS DURANTE A FORMAÇÃO ACADÊMICA NA PERCEPÇÃO DOS ALUNOS
}

\section{MANAGER SKILLS DEVELOPED DURING UNDERGRADUATE IDENTIFIED BY THE STUDENTS}

\author{
Camila Bittencourt do Nascimento, \\ Fucape Business School \\ https://orcid.org/0000-0001-5026-5355 \\ Arilda Magna Campagnaro Teixeira \\ Fucape Business School \\ https://orcid.org/0000-0002-7697-0439
}

\begin{abstract}
RESUMO
Este estudo teve como objetivo apontar as competências percebidas pelos estudantes de Administração do estado do Maranhão que foram desenvolvidas durante seus cursos. Justificase porque acrescentará um ângulo de discussão sobre as qualidades desses cursos - a percepção do aluno sobre suas competências - enquanto a pesquisas existentes concentraram-se nas qualidades dos cursos. Utilizou uma pesquisa quantitativa de caráter descritivo, com corte transversal, por meio da coleta de dados primários por acessibilidade. Os resultados foram obtidos através de estatísticas descritivas e regressão linear múltipla. As estatísticas descritivas apontaram que alguns alunos da IES Pública e das Privadas tenderam a concordar quanto ao desenvolvimento das competências e habilidades; enquanto outros não - os desvios-padrão das médias das respostas indicaram dispersão entre opiniões. As estimativas da regressão, ao nível de 5\% de confiança, apontaram que, para a IES pública, somente o Perfil Profissiográfico mostrou-se estatisticamente significante para explicar o perfil do egresso. Para as IES Privadas, mostraram-se estatisticamente significantes, ao nível de 5\% de confiança, as variáveis, Perfil Profissiográfico, Job Description e "trabalhar na área administrativa". Esses resultados sugerem que os alunos das IES públicas percebem menos competências e habilidades que estão lhes sendo desenvolvidas do que os alunos das IES Privadas.
\end{abstract}

Palavras-chave: Ensino Superior; Administração; Desenvolvimento de Competências; Percepção dos alunos.

\begin{abstract}
This paper aimed to identify the competencies perceived by the students of Business Administration in the state of Maranhão that were developed during their courses. It is justified because it will add an angle of discussion on the qualities of these courses - the student perception about the competencies - while the current researches concentrated on the quality of the courses. It was used a descriptive character research, with cross-sectional cut, through the data collection of primary data by accessibility. The results were obtained through descriptive statistics and multiple linear regression. The descriptive statistics showed that some Public and Private IES students tended to agree on the development of the competencies and habilities; while others did not - the standard-deviations of the average of the answers indicated dispersion among opinions. The estimates of the regression, at $5 \%$ level of confidence, showed
\end{abstract}


that, for the Public IES, only the Profissiographic Profile showed statistically significant to explain the egress profile. For the Private IES, the variables showed statistically significant, at the level of 5\% of confidence, Profissiographic Profile, Job Description and "working in the administrative area". These results suggest that the Public IES students notice less competencies and abilities that are being developed to them than the Private IES students.

Keywords: Higher Education; Business Administration; Competencies Development; Perception of students.

\section{INTRODUÇÃO}

O aumento da competição entre as organizações obrigou-as a serem mais eficientes o que, por sua vez, fez com que passassem a procurar profissionais, capazes de potencializar suas capacidades produtivas através de comportamentos ágeis, assertivos e estratégicos (PERIN et al., 2009; MUSHTAQ; KHAN, 2012; CHING; SILVA; TRENTIN, 2014).

Essa tendência na profissão do Administrador reiterou o papel das Instituições de Ensino Superior (IES) no processo de geração da empregabilidade desses profissionais, tendo em vista que são os cursos por elas oferecidos que desenvolveriam as habilidades e as competências requeridas pelo mercado de trabalho (AMATUCCI, 2009; MUSHTAQ; KHAN, 2012; RIBEIRO; MANCEBO, 2013).

Entretanto subsistem alguns elementos que podem comprometer o desenvolvimento das habilidades e competências desses profissionais. Dentre eles, a evolução das metodologias e didáticas adotadas (PFEFFER; FONG, 2003), o nível de qualificação dos docentes (KARAWEJCZYK; ESTIVALETE, 2002; NASSIF; HANASHIRO, 2008), e o acesso às tecnologias adequadas (HOCAYEN-DA-SILVA; CASTRO; MACIEL, 2008).

O Conselho Federal de Administração define o perfil do administrador integrado por habilidades e competências relacionadas ao pensamento estratégico, à liderança, à ética e ao profissionalismo (MELLO; MELLO JR; MATTAR, 2011). Martina, Hana e Jiri (2012), definiram como sendo competências de gestão a capacidade de liderança, o profissionalismo, a atitude, o dinamismo, a organização, o pensamento sistêmico, a comunicação e o relacionamento interpessoal. Chong (2013) atribui como competências essenciais para o profissional em Administração aquelas que estão relacionadas ao planejamento, à organização e à liderança, por meio da motivação.

A literatura que tem discutido as competências requeridas para esses profissionais está concentrada no aspecto da qualidade do ensino superior, e no mercado de trabalho. Pouca atenção tem sido dada à percepção dos estudantes sobre essas competências (BRANDÃO; BORGES-ANDRADE, 2008; BRUNSTEIN; HEIDRICH; AMARO, 2016). Para preencher essa lacuna este artigo teve como objetivo apontar as competências percebidas pelos estudantes de Administração do estado do Maranhão que foram desenvolvidas durante suas formações acadêmico-profissionais.

A justificativa para a escolha do Maranhão é que a gestão do setor público desse estado foi reformulada nos anos 1990 levando-o a fazer investimentos em tecnologia para processos de gestão e em capital humano. Esse processo resultou no aumento de Instituições de ensino Superior (IES) pública e privada; e na subsequente necessidade de acompanhar a qualidade do ensino nessas instituições (MOURA; MOURA, 2015).

Para apontar as competências percebidas pelos estudantes durante suas formações acadêmico-profissionais, foi utilizado como metodologia de pesquisa o método quantitativo 
Survey, com corte transversal, por meio de coleta de dados primários, através de aplicação de questionário estruturado com perguntas objetivas, em escala Likert, com amostra não probabilística por acessibilidade.

Essa perspectiva de análise é relevante para as IES, pois poderá indicar para os agentes educacionais o que está sendo diligenciado e o que pode ser aprimorado. A linha de discussão que se propõe distingue-se das anteriores por apontar a avaliação dos estudantes acerca da efetividade do desenvolvimento do perfil definido pelos projetos pedagógicos de seus cursos, e a avaliados pelo Ministério de Cultura e Educação (MEC) (ECHEVESTE et al., 1999; INEP, 2005; IIZUKA; MORAES, 2014). Sob esse ângulo de interpretação espera-se identificar a percepção dos alunos sobre as habilidades e competências desenvolvidas pelos seus cursos, que são parâmetros para as avaliações institucionais feitas pelos órgãos reguladores, e também para a empregabilidade desses alunos.

Foi feita pesquisa de campo, através da aplicação de questionário, em uma IES pública e em duas IES privadas em São Luís-MA, obtendo 313 respostas válidas. A caracterização das amostras demonstrou similaridade entre os grupos pesquisados, o que permitiu validá-las. A estatística descritiva indicou tendência à concordância dos respondentes em relação às afirmativas de todos os construtos. A análise fatorial confirmatória demonstrou a validade dessas afirmativas - todas as cargas fatoriais foram estatisticamente significantes. Os resultados da regressão linear múltipla apontaram que os estudantes das IES privadas consideram que seus cursos lhes desenvolveram perfil profissiográfico e job description; e consideram que trabalhar na área contribui para formar o perfil do Administrador. Em contrapartida, os estudantes da IES pública, somente perceberam o desenvolvimento do perfil profissiográfico.

\section{REFERENCIAL TEÓRICO}

As complexas e multifacetadas organizações demandam um Administrador com perfil multifário, dinâmico, e inovador, capaz de atender às exigências sociais, mercadológicas e tecnológicas (CHING; SILVA; TRENTIN, 2014). Logo, o desafio das IES e de todos os atores educacionais é alinhar o perfil do estudante ao perfil do futuro profissional, desenvolvendo as habilidades e competências determinadas pela Resolução CNE/CSE no 04/2005 e as demandadas pelo mercado (BURNIER 2001; INEP 2005).

Amatucci (2009) atribuiu três subperfis para o Administrador: o Profissiográfico habilidades e competências invariantes, pautadas historicamente em teorias; o Job Description - habilidades e competências exigidas pelos cargos/funções (práticas gerenciais); e Competência - habilidades e competências demandadas pelo mercado de trabalho (práticas mercadológicas) (PIZZINATTO, 1999; AMATUCCI, 2009; ARAÚJO et al., 2014).

\section{Perfil Profissiográfico}

O objetivo central dos Conselhos educacionais é desenvolver nos discentes habilidades e competências através de técnicas e estratégias metodológicas. Então, as IES elaboram seus Projetos Pedagógicos definindo o Perfil Profissiográfico e deliberando as estratégias metodológicas para o desenvolvimento das competências e habilidades que os egressos deverão possuir, fundamentados pela Resolução CNE/CSE nº 04/2005 (AMATUCCI, 2009; INEP, 2005) - Quadro 1. 
Quadro 1: Competências e habilidades a serem desenvolvidas nos egressos pelas IES

Tomada de Decisão Gerencial, por meio do reconhecimento dos problemas, do planejamento e da ação estratégica.

Comunicação Interpessoal.

Gerenciamento e controle do processo produtivo.

Desenvolvimento de raciocínio lógico, crítico e analítico.

Gestão inovadora, por meio de iniciativa e abertura a mudanças.

Resiliência.

Compreensão da complexidade administrativa elaborando, implementando e gerenciando os projetos organizacionais.

Capacidade de atuar em consultoria e perícias organizacionais.

Fonte: Artigo 4º da Resolução CNE/CES nº 04, de 13 de julho de 2005.

Para implementá-lo precisam contratar docentes capacitados, em condições de sustentar um ensino de qualidade (KARAWEJCZYK; ESTIVANELE, 2002; HOCAYEN-DA-SILVA; CASTRO; MACIEL, 2008). Por sua vez, os docentes, para serem capazes de participar desse processo devem reestruturar e inovar suas didáticas e assumir o papel de agente principal desse processo (ARAÚJO et al., 2014).

Para desenvolver as habilidades propostas o estudante necessita domínio de raciocínio analítico, lógico e sistêmico, que o permita analisar, questionar e confrontar teorias e práticas (SONAGLIO; GODOI; SILVA, 2013); ter acesso a metodologias aprimoradas, como os jogos de empresas, cases, atividades práticas supervisionadas, simulações, entre outras, com o objetivo de treinar e desenvolver a capacidade de resolução de problemas e tomada de decisão gerencial (SENGE et al., 2012).

A proposta de resolução de problemas fictícios remete ao aluno às experiências com situações reais, ampliando sua visão no processo de tomada de decisão, cooperando com as habilidades interpessoais e grupais (MARQUARDT; WADDILL, 2004; REVANS, 2011). Fornecendo informações para o desenvolvimento das competências atinentes a potenciais líderes, aprimorando a capacidade de resiliência e comunicação (HANSON, 2010; SONAGLIO; GODOI; SILVA, 2013).

Nesse sentido, o processo de preparação do discente contém elementos indissociáveis técnicas e práticas atuais e futuras, o saber e o fazer - que configuram a complexidade da futura profissão, que demanda por profissionais com visão inovadora, global e estratégica (ARAÚJO; FARIAS, 2008; ARAÚJO et al., 2014).

A complexidade administrativa torna inexorável a busca pela eficiência organizacional para alinhar os processos às estratégicas. Estas, por sua vez, tornam indispensáveis, a geração de feedback por meio do acompanhamento regular dos sistemas implantados (PATAH e CARVALHO, 2009). Esse gerenciamento deverá ser liderado por um profissional perspicaz, com conhecimento técnico, liderança, agilidade e dinamismo, negociação, proatividade e flexibilidade (KERZNER, 2013).

Godemann et al. (2011) apontaram que os cursos de Administração criaram estratégias inter e multidisciplinar para desenvolver essas habilidades interpessoais, análise crítica e conhecimento para resolução de problemas globais, compactuados à peculiaridade organizacional e mercadológica.

Então, equipar tecnicamente os universitários para que eles possam atuar com autoconfiança no mercado de trabalho se torna uma responsabilidade intransferível das IES. Uma grade curricular de excelência e a viabilização de estágios curriculares com o devido 
acompanhamento são alguns dos requisitos que não há como se omitir. Outras atividades satélites, tais como a promoção de Programas de Desenvolvimento de Líderes e Ciclos de Palestras, Seminários, Cursos e Conferências demonstram o comprometimento e um diferencial competitivo, conforme continuação das abordagens a seguir (HAAN, 2006; CHING; SILVA; TRENTIN, 2014).

\section{Perfil Job Description}

As Organizações, como impulsionadoras do desenvolvimento e equilíbrio socioeconômico de um país, necessitam de capital intelectual como diferencial competitivo, para melhorar os resultados e sobrepujar a concorrência (WRIGHT et al., 2010).

O perfil Job Description foi denominado por Chong (2013) como aquele que integra o core competence basilar para a função de gerência: habilidades de comunicação, relacionamento interpessoal, capacidade de negociação, capacidade técnica, atitude e moral. As organizações distribuem suas estratégias conforme suas especificidades tecnológicas, humanas, processuais e gerenciais, assim como a escolha e adequação das competências e habilidades pertinentes ao atendimento de seus objetivos (MOURA; BITENCOURT, 2006; AMATUCCI, 2009). Elas preparam seus gerentes desenvolvendo as core competence exigidas pelo cargo (MARTINA; HANA; JIRI, 2012).

Os estudos de Brandão e Borges-Andrade (2008), apontaram que é a aprendizagem educacional que contribui para a evolução das competências. E para Amatucci (2009) elas são a fórmula do sucesso das empresas, uma vez que são como parâmetros estratégicos para tomadas de decisão.

Perfil de Competência

As emergentes e incessantes inovações tecnológicas exigem um posicionamento estratégico das organizações capaz de gerar um diferencial competitivo para enfrentar a concorrência (PERIN et al., 2009). Para adota-lo são necessários profissionais capazes de utilizar e aplicar as tecnologias disponíveis. Ou seja, com as competências basilares para enfrentar a competição dos mercados - resiliência, criatividade, inovação, agilidade em raciocínio e decisões, comunicação oral e escrita, visão global, atitude empreendedora, relacionamento interpessoal e ética (SANT'ANNA; MORAES; KILIMNIK, 2005; MOURA; BITENCOURT, 2006; MARTINA; HANA; JIRI, 2012; WEAVER; KULESZA, 2014; GRUPTA et al., 2014). Essas condições do mercado de trabalho impõem frequentes aperfeiçoamentos aos Administradores para estarem sempre capazes de manter suas posições nesse mercado (WRIGHT et al., 2010).

Mello, Mello Jr e Mattar (2011) evidenciaram que o perfil do administrador é constituído por habilidades e competências relacionadas ao pensamento sistêmico e global, à visão estratégica, à liderança e coordenação de equipes, à ética, e ao profissionalismo. Para Vieira e Luz (2005), para ter tal perfil, é necessário desenvolver competências comportamentais e transversais. Peleckis e Peleckienè (2013) ratificaram que as competências comportamentais são essenciais e devem ser desenvolvidas no indivíduo como forma a contribuir para seu desempenho e crescimento dentro das organizações gerando eficácia, eficiência e efetividade. 
A Qualidade do Ensino de Administração no Brasil

A primeira escola de Administração no Brasil é de 1954, com o perfil das escolas de negócios norte-americanas da época, que se propunham formar profissionais com conhecimentos de visão interna da organização, pautados pela divisão de trabalho e coordenação de atividades industriais especializadas (MOTTA, 1983).

Esse perfil precisou ser modificado diante a dinâmica e a complexidade do ambiente de negócios, que gradativamente passou a exigir profissionais com capacidade de pensar e agir estrategicamete (HOCAYEN-DA-SILVA; CASTRO; MACIEL, 2008). Nessa perspectiva, a qualidade do ensino tornou-se crucial; e no seu rastro, a das IES também (MINTZBERG; 2006; NASSIF; HANASHIRO, 2008). Principalmente, devido ao crescimento incontido de cursos de Administração no Brasil; cujo ritmo é uma ameaça à uniformidade e qualidade desses cursos e, consequentemente, ao perfil desejado do seu egresso (AMATUCCI, 2009; WEISE, et al., 2014).

A proposta de identificar a percepção do estudante de Administração quanto ao seu preparo para o exercício da profissão é uma iniciativa oportuna para se captar os desafios que a sustentação da qualidade desses cursos enfrenta.

\section{PROCEDIMENTOS METODOLÓGICOS}

\section{Estratégia Empírica}

A pesquisa utilizou metodologia quantitativa, de caráter descritivo, com corte transversal. Seu universo foram alunos do ensino superior. A amostra não probabilística por acessibilidade, foi formada por alunos do $5^{\circ}$ ao $8^{\circ}$ período do curso de Administração - com mais de $50 \%$ do curso concluído.

A coleta de dados primários foi por meio de aplicação de questionários padronizados, com questões fechadas, enviados para os estudantes, no período de 6 junho a 10 de agosto de 2016, por e-mail, redes sociais, mensagens por celular, plataforma typerform, aplicativo Whatsapp, e aplicados diretamente nos alunos de IES das redes pública e privada, na cidade de São Luís (MA).

Para validar o questionário foi realizado um pré-teste aplicado presencialmente para 15 alunos. Como os respondentes não tiveram dificuldade de entendimento das afirmações considerou-se o questionário validado. Em seguida procedeu-se a aplicação. Foram coletados 367 questionários, mas 54 foram descartados porque eram de respondentes que não estavam nos últimos períodos. Assim a amostra analisada foi de 313 questionários válidos.

As afirmações contidas no questionário foram adaptadas da escala de Amatucci (2009) e fazem referência a dezessete variáveis, desmembradas em 20 itens, relacionadas a três construtos: Perfil Profissiográfico (PP), Perfil Job Description (PJD), e Perfil de Competência (PC). O questionário foi dividido em quatro grupos. O primeiro, com duas perguntas de controle - qual curso de graduação e qual período que está cursando. O segundo, com os quesitos para avaliar a percepção do respondente em relação à sua formação. $\mathrm{O}$ terceiro com os três construtos, Perfil Profissiográfico, Perfil Job Description, e Perfil de competência. O quarto, para identificar as características sociodemográficas, rotinas escolares e acesso ao mercado de trabalho dos respondentes. As respostas para os segundo e terceiro grupos estão em escala Likert de um a cinco - em que um é "discordo totalmente" e cinco "concordo totalmente". 
Características da Amostra

A amostra foi segmentada em grupo de alunos de uma IES pública (121 respondentes), e grupo de alunos de duas IES privadas (192 respondentes) - Tabelas 1 e 2 . Na pública $46.28 \%$ era do sexo feminino e $53.72 \%$ masculino. Nas privadas, $68,75 \%$ do sexo feminino e $31,25 \%$ masculino. A faixa etária predominante na pública estava entre 18 e 27 anos (79,3\%); e nas privadas 23 a 32 anos $(56,3 \%)$ - Tabela 1.

TABELA 1. CARACTERÍSTICAS DEMOGRÁFICAS DA AMOSTRA

\begin{tabular}{l|c|c|c|c}
\hline \multirow{2}{*}{ CARACTERÍSTICA } & \multicolumn{2}{|c|}{ PÚBLCA } & \multicolumn{2}{c}{ PRIVADA } \\
\cline { 2 - 5 } & $\mathrm{n}^{\mathbf{0}}$ & part \% & $\mathrm{n}^{\mathbf{o}}$ & part \% \\
\hline GENERO & & & & \\
Feminino & 56 & 46.28 & 132 & 68.75 \\
Masculino & 65 & 53.72 & 60 & 31.25 \\
Total & $\mathbf{1 2 1}$ & $\mathbf{1 0 0}$ & $\mathbf{1 9 2}$ & $\mathbf{1 0 0}$ \\
\hline IDADE & & & & \\
Entre 18 A 22 anos & 73 & 60.33 & 42 & 21.87 \\
De 23 A 27 anos & 23 & 19.01 & 58 & 30.21 \\
De 28 A 32 anos & 10 & 8.27 & 50 & 26.05 \\
De 33 A 37 anos & 5 & 4.13 & 24 & 12.50 \\
De 38 A 42 anos & 4 & 3.31 & 9 & 4.68 \\
De 43 A 47 anos & 6 & 4.96 & 3 & 1.56 \\
De 48 A 54 anos & 0 & 0 & 6 & 3.12 \\
Total & $\mathbf{1 2 1}$ & $\mathbf{1 0 0}$ & $\mathbf{1 9 2}$ & $\mathbf{1 0 0}$ \\
\hline RENDA FAMILIAR & & & & \\
Até 2 sal mínimos & 47 & 38.84 & 99 & 51.56 \\
De 3 a 4 sal mínimos & 44 & 36.36 & 70 & 36.46 \\
De 5 a 6 sal mínimos & 18 & 14.88 & 17 & 8.85 \\
Acima 6 sal mínimos & 12 & 9.92 & 6 & 3.13 \\
Total & $\mathbf{1 2 1}$ & $\mathbf{1 0 0}$ & $\mathbf{1 9 2}$ & $\mathbf{1 0 0}$ \\
\hline \hline
\end{tabular}

Fonte: Dados da pesquisa. Elaborado pelas autoras

Os resultados para o perfil socioeconômico indicaram que 75,2\% dos alunos das privadas tinham renda familiar de até quatro salários mínimos; e na pública, $88 \%$. A maioria dos estudantes das privadas cursaram o ensino médio em escolas públicas -Tabela 1.

Essas estatísticas ratificam o perfil socioeconômico da maioria da população do estado do Maranhão: renda muito baixa, índices de pobreza elevados, e limitado acesso a informações e conhecimento de cunho intelectual e cultural (BRITTO et al., 2008; PESSOA; MARTINS, 2015).

Para as características das rotinas dos respondentes - Tabela 2 - os resultados indicam que $29,7 \%$ recorreram a bolsa de estudos ou financiamentos; $78,5 \%$ da pública e $90,6 \%$ das privadas disseram-se comprometidos em alcançar perfil profissional adequado para o mercado. A escolha do curso foi motivada pela perspectiva de rápido ingresso no mercado de trabalho para $32,8 \%$ das privadas, e $23,1 \%$ da pública. Em relação à preparação para o mercado de trabalho - assistência da IES pública e privadas aos programas de estágio, de bolsas e financiamentos de pesquisas científicas - os resultados indicam que a maioria dos estudantes, quer sejam da rede pública $(63,6 \%)$, quer da privada (50,5\%), está sendo inserido no mercado de trabalho por meio do estágio o que, para Rocha-de-Oliveira e Piccinini (2011), é a principal forma de experiência profissional. 
TABELA 2: CARACTERÍSTICAS DA ROTINA ESCOLAR DA AMOSTRA

\begin{tabular}{|c|c|c|c|c|}
\hline \multirow[b]{2}{*}{ CARACTERÍSTICA } & \multicolumn{2}{|c|}{ PÚBLICA } & \multicolumn{2}{|c|}{ PRIVADA } \\
\hline & $\mathrm{n}^{\mathrm{o}}$ & part $\%$ & $\mathrm{n}^{\mathrm{o}}$ & part $\%$ \\
\hline ESTAGIOU & & & & \\
\hline $\operatorname{Sim}$ & 77 & 63.64 & 97 & 50.52 \\
\hline Não & 44 & 36.36 & 95 & 49.48 \\
\hline Total & 121 & 100 & 192 & 100 \\
\hline \multicolumn{5}{|c|}{ BOLSA DE ESTUDO OU FINANCIAMENTO } \\
\hline Não, pois meu curso é gratuito & 121 & 100 & 0 & 0 \\
\hline Não, meu curso não é gratuito & 0 & 0 & 113 & 58.85 \\
\hline ProUni integral & 0 & 0 & 25 & 13.02 \\
\hline ProUni parcial & 0 & 0 & 7 & 3.65 \\
\hline FIES integral & 0 & 0 & 16 & 8.33 \\
\hline FIES parcial & 0 & 0 & 9 & 4.69 \\
\hline Financiamento da própria IES & 0 & 0 & 7 & 3.65 \\
\hline Sim. Outros & 0 & 0 & 15 & 7.81 \\
\hline Total & 121 & 100 & 192 & 100 \\
\hline \multicolumn{5}{|l|}{ COMPROMETIMENTO } \\
\hline Muito comprometido & 38 & 31.40 & 67 & 34.90 \\
\hline Comprometido & 57 & 47.11 & 107 & 55.73 \\
\hline Nem comprometido nem descomprometido. & 22 & 18.18 & 15 & 7.81 \\
\hline Pouco comprometido & 4 & 3.31 & 2 & 1.04 \\
\hline Descomprometido & 0 & 0 & 1 & 0.52 \\
\hline Total & 121 & 100 & 192 & 100 \\
\hline \multicolumn{5}{|c|}{ TIPO DE ESCOLA QUE CURSOU O ENSINO MÉDIO } \\
\hline Todo em escola pública & 67 & 55.37 & 136 & 70.83 \\
\hline Todo em escola particular & 47 & 38.84 & 34 & 17.71 \\
\hline Maior parte em escola pública & 1 & 0.83 & 16 & 8.33 \\
\hline Maior parte em escola particular & 4 & 3.31 & 6 & 3.12 \\
\hline Todo no exterior & 2 & 1.65 & 0 & 0 \\
\hline Parte no Brasil/Parte no exterior & 0 & 0 & 0 & 0 \\
\hline Total & 121 & 100 & 192 & 100 \\
\hline \multicolumn{5}{|l|}{ MOTIVO DE ESCOLHA DO CURSO } \\
\hline Inserção rápida no mercado & 28 & 23.14 & 63 & 32.81 \\
\hline Influência Familiar & 9 & 7.44 & 12 & 6.25 \\
\hline Valorização Profissional & 6 & 4.96 & 38 & 19.79 \\
\hline Prestígio Social & 0 & 0 & 0 & 0 \\
\hline Vocação & 49 & 40.50 & 46 & 23.96 \\
\hline Baixa Concorrência & 3 & 2.48 & 1 & 0.52 \\
\hline Outro Motivo & 26 & 21.49 & 32 & 16.67 \\
\hline Total & 121 & 100 & 192 & 100 \\
\hline \multicolumn{5}{|l|}{ BOLSA DE PESQUISA } \\
\hline Sim & 4 & 3.31 & 0 & 0 \\
\hline Não & 117 & 96.69 & 192 & 100.00 \\
\hline Total & 121 & 100 & 192 & 100 \\
\hline
\end{tabular}


Mas, em contrapartida, em termos de bolsa de iniciação científica, tantos os alunos da IES pública quanto das privadas, não recebem essa modalidade de bolsa - Tabela 3. Essa estatística denota que as IES não estão dando a devida atenção para outro possível segmento profissional para o aluno, a academia, que também é mercado de trabalho.

Quanto aos indicadores de empregos desses estudantes, na IES pública, 67,8\% estão desempregados; $63,6 \%$ procuraram emprego durante a graduação; e 61,2\% ainda não trabalham e nem trabalharam na área administrativa. Nas IES privadas, $69,8 \%$ dos alunos estão empregados; $76 \%$ procuraram emprego durante o curso; e a maioria $(53,6 \%)$ está trabalhando ou já trabalhou na área administrativa - Tabela 3.

TABELA 3: CARACTERÍSTICAS DO PROCESSO DE ACESSO AO MERCADO DE TRABALHO

\begin{tabular}{|c|c|c|c|c|}
\hline \multirow{2}{*}{ CARACTERÍSTICA } & \multicolumn{2}{|c|}{ PÚBLICA } & \multicolumn{2}{|c|}{ PRIVADA } \\
\hline & $\mathrm{n}^{\mathrm{o}}$ & part \% & $\mathrm{n}^{\mathrm{o}}$ & part $\%$ \\
\hline $\begin{array}{l}\text { TRABALHA OU TRABALHOU NA ÁREA ADMINISTRATIVA } \\
\text { Sim } \\
\text { Não } \\
\text { Total }\end{array}$ & $\begin{array}{r}47 \\
74 \\
\mathbf{1 2 1}\end{array}$ & $\begin{array}{c}38.84 \\
61.16 \\
\mathbf{1 0 0} \\
\end{array}$ & $\begin{array}{c}103 \\
89 \\
192\end{array}$ & $\begin{array}{c}53.65 \\
46.35 \\
\mathbf{1 0 0}\end{array}$ \\
\hline $\begin{array}{l}\text { PROCUROU EMPREGO DURANTE A GRADUAÇ̃̃O } \\
\text { Sim } \\
\text { Não } \\
\text { Total }\end{array}$ & $\begin{array}{r}77 \\
44 \\
\mathbf{1 2 1}\end{array}$ & $\begin{array}{c}63.64 \\
36.36 \\
\mathbf{1 0 0}\end{array}$ & $\begin{array}{c}146 \\
46 \\
192\end{array}$ & $\begin{array}{c}76.04 \\
23.96 \\
\mathbf{1 0 0}\end{array}$ \\
\hline $\begin{array}{l}\text { TIPO DE EMPREGO } \\
\text { Em empresa privada } \\
\text { Em empresa pública } \\
\text { Desempregado } \\
\text { Total }\end{array}$ & $\begin{array}{c}33 \\
6 \\
82 \\
\mathbf{1 2 1} \\
\end{array}$ & $\begin{array}{c}27.27 \\
4.96 \\
67.77 \\
\mathbf{1 0 0} \\
\end{array}$ & $\begin{array}{c}116 \\
18 \\
58 \\
\mathbf{1 9 2} \\
\end{array}$ & $\begin{array}{c}60.42 \\
9.38 \\
30.21 \\
\mathbf{1 0 0} \\
\end{array}$ \\
\hline
\end{tabular}

Fonte: Dados da pesquisa. Elaborado pelas autoras

Estatística Descritiva

Os resultados das Tabelas 4 e 5 indicam que os respondentes, tanto da IES pública quanto das privadas, apenas tenderam a concordar com as afirmações em relação aos construtos profissiográfico, job desciption e competência. O que distinguiu a opinião de um grupo (pública), do outro (privadas), é que para o primeiro, há menos dispersão nas respostas sugerindo que as opiniões tendem a se convergir; diferentemente do segundo em que há mais dispersão.

Dentro dos construtos, houve concordância entre os respondentes das instituições pública e privadas em relação a três afirmações do construto job description: "compreende a missão e os valores da organização", "tenha ética" e "tenha atitude". E na pública, houve concordância com a afirmação "compreende a complexidade administrativa". 
Tabela 4: ESTATÍSTICA DESCRITIVA - Instituição Pública

\section{VARIÁ VEIS DEPENDENTES (VD)}

Eu me sinto muito bem capacitado pela minha Faculdade para atuar na área Administrativa.

Eu tenho conhecimento acerca das competências e habilidades necessárias a um administrador e que são requeridas pelo mercado.

A formação que a minha Faculdade está me dando está alinhada com o que o mercado de trabalho está exigindo do Administrador atualmente

O curso de Administração oferecido pela minha Faculdade está contribuindo para que eu adquira competências para desenvolver o perfil exigido no mercado de trabalho.

\section{PERFIL PROFISSIOGRÁFICO}

Estabeleça sintonia na comunicação com indivíduos ou equipes (comunicação interpessoal).

Desenvolva Raciocínio lógico, crítico e analítico

Compreenda a complexidade administrativa.

Inove diante das dificuldades das empresas, assumindo as consequências das decisões tomadas (Gestão Inovadora)

Atue com integridade e de maneira consistente, conseguindo se adaptar as mudanças.

Compreenda o cenário do mercado e das empresas para a tomada de decisão.

Compreenda e selecione as estratégias que atendam os objetivos individual e da equipe.

Compreenda e selecione as estratégias que atendam os objetivos institucionais.

\section{JOB DESCRIPTION}

Entenda, antecipe e procure responder às necessidades do mercado e das empresas

Possua capacidade de negociação com os fornecedores, clientes, sócios-proprietários, acionistas... (todos os stakeholders)

Compreenda a missão e valores da Organização.

Compreenda as competências essenciais exigidas nos cargos e funções da Organização.

Tenha capacidade técnica e conhecimento.

Tenha ética e moral

Tenha atitude.

Desenvolva habilidade em lidar com diferenças culturais das pessoas.

\begin{tabular}{l|c|c}
\hline Desenvolva habilidade em lidar com diferenças culturais das pessoas. & 3,85 & 1,1 \\
\hline \multicolumn{1}{c|}{ COMPETÊNCIA } & $\mathbf{3 , 9 3}$ & $\mathbf{0 , 8 1}$ \\
\hline Possua visão do sistema social-econômico global, para pensar e agir estrategicamente. & 3,98 & 0,86 \\
\hline Desenvolva capacidade de inovar, para atendimento das necessidades dos clientes. & 3,8 & 1,02 \\
\hline Possua capacidade de adaptação frente às mudanças. & 3,97 & 0,93 \\
\hline Possua preocupação com o meio-ambiente e com o desenvolvimento sustentável. & 3,95 & 1,01 \\
\hline
\end{tabular}

Fonte: Dados da Pesquisa. Elaborado pelas autoras 
Tabela 5: ESTATÍSTICA DESCRITIVA - Instituições Privadas

\begin{tabular}{|c|c|c|}
\hline & Média & DP \\
\hline VARIÁVEIS DEPENDENTES & 3,76 & $\mathbf{0 , 8 1}$ \\
\hline Eu me sinto muito bem capacitado pela minha Faculdade para atuar na área Administrativa. & 3,56 & 1,03 \\
\hline $\begin{array}{l}\text { Eu tenho conhecimento acerca das competências e habilidades necessárias a um } \\
\text { administrador e que são requeridas pelo mercado. }\end{array}$ & 3,77 & 0,86 \\
\hline $\begin{array}{l}\text { A formação que a minha Faculdade está me dando está alinhada com o que o mercado de } \\
\text { trabalho está exigindo do Administrador atualmente }\end{array}$ & 3,8 & 1 \\
\hline $\begin{array}{l}\text { O curso de Administração oferecido pela minha Faculdade está contribuindo para que eu } \\
\text { adquira competências para desenvolver o perfil exigido no mercado de trabalho. }\end{array}$ & 3,93 & 0,97 \\
\hline $\begin{array}{l}\text { PROFISSIOGRÁFICO } \\
\end{array}$ & 3,79 & $\mathbf{0 , 9}$ \\
\hline Estabeleça sintonia na comunicação com indivíduos ou equipes (comunicação interpessoal). & 3,9 & 0,94 \\
\hline Desenvolva Raciocínio lógico, crítico e analítico & 3,76 & 1,1 \\
\hline Compreenda a complexidade administrativa. & 3,78 & 1,05 \\
\hline $\begin{array}{l}\text { Inove diante das dificuldades das empresas, assumindo as consequências das decisões } \\
\text { tomadas (Gestão Inovadora) }\end{array}$ & 3,65 & 1,1 \\
\hline Atue com integridade e de maneira consistente, conseguindo se adaptar as mudanças. & 3,88 & 1,06 \\
\hline Compreenda o cenário do mercado e das empresas para a tomada de decisão. & 3,92 & 1,03 \\
\hline Compreenda e selecione as estratégias que atendam os objetivos individual e da equipe. & 3,69 & 1,07 \\
\hline Compreenda e selecione as estratégias que atendam os objetivos institucionais. & 3,73 & 1,06 \\
\hline JOB DESCRIPTION & 3,89 & $\mathbf{0 , 8 8}$ \\
\hline Entenda, antecipe e procure responder às necessidades do mercado e das empresas & 3,7 & 1,09 \\
\hline $\begin{array}{l}\text { Possua capacidade de negociação com os fornecedores, clientes, sócios-proprietários, } \\
\text { acionistas... (todos os stakeholders) }\end{array}$ & 3,64 & 1,05 \\
\hline Compreenda a missão e valores da Organização. & 4,05 & 0,94 \\
\hline Compreenda as competências essenciais exigidas nos cargos e funções da Organização. & 3,93 & 0,98 \\
\hline Tenha capacidade técnica e conhecimento. & 3,77 & 1,07 \\
\hline Tenha ética e moral & 4,02 & 1,06 \\
\hline Tenha atitude. & 4,04 & 1,04 \\
\hline Desenvolva habilidade em lidar com diferenças culturais das pessoas. & 3,94 & 1,05 \\
\hline Competência & 3,8 & 0,94 \\
\hline Possua visão do sistema social-econômico global, para pensar e agir estrategicamente. & 3,83 & 1,05 \\
\hline Desenvolva capacidade de inovar, para atendimento das necessidades dos clientes. & 3,84 & 1,11 \\
\hline Possua capacidade de adaptação frente às mudanças. & 3,8 & 1,12 \\
\hline Possua preocupação com o meio-ambiente e com o desenvolvimento sustentável. & 3,73 & 1,12 \\
\hline
\end{tabular}

Fonte: Dados da pesquisa. Elaborado pelas autoras

\section{Modelo Teórico}

Os dados foram interpretados através de teste de diferença de média, análise fatorial confirmatória, e regressão linear múltipla.

\section{Teste de Diferença de Média}

O teste de comparação de médias, realizado para comparar as respostas dos alunos das IES privadas com as respostas dos alunos da pública, indicou que não há diferença de opiniões entre os grupos - Tabela 6 - ratificando a qualidade da estatística. 
Análise Fatorial Confirmatória

Para identificar a validade das variáveis, foram estimadas suas cargas fatoriais por maxiverossimilhança, através do modelo Generalized Structural Equation Model (gsem), por serem variáveis ordinais (categóricas). Foi feita apenas a análise confirmatória porque a escala utilizada já está validada.

Regressão Linear Múltipla

Estimou os componentes do Perfil do Egresso do Curso de Administrador (PEADM) que são estatisticamente relevantes para explicar esse perfil. Em outras palavras, quais competências para a carreira do Administrador os estudantes perceberam que lhes foram desenvolvidas pelo curso - Equação (1).

$$
\mathrm{PEADM}=\beta_{0}+\sum_{\mathrm{i}=1}^{3} \beta \mathrm{i} \mathrm{Xi}+\text { Controles }+E i
$$

Em que:

Variáveis explicativas:

$\mathrm{X}_{1}=$ Perfil Profissiográfico;

$\mathrm{X}_{2}=$ Perfil Job Description;

$\mathrm{X}_{3}=$ Perfil de Competência;

Variáveis de Controles: Gênero; Idade; Renda familiar; Estágio; Comprometimento; Bolsa Pesquisa Científica; Trabalho na área administrativa; Emprego

O teste para identificar a normalidade dos resíduos (Shapiro-Wilk) apontou que não são normalmente distribuídos - Tabela 6.

Tabela 6 - TESTE NORMALIDADE SHAPIRO-WILK

\begin{tabular}{c|c|c|c|c|c}
\hline Modelo & Núm. observações & Pr(skewness) & $\operatorname{Pr}$ (Kurtosis) & adj chi2(2) & Prob > chi2 \\
\hline SEM CONTROLE & 313 & 0,0001 & 0,0194 & 17,07 & 0,0002 \\
\hline COM CONTROLE & 313 & 0,0005 & 0,0567 & 13,72 & 0,001 \\
\hline
\end{tabular}

Fonte: dados da pesquisa. Elaborado pelas autoras

Então foi feita análise gráfica (Jarque-Bera), cujo resultado sugeriu que os resíduos são normalmente distribuídos - Figuras 1 e 2. 
Figura 1 - SEM CONTROLE

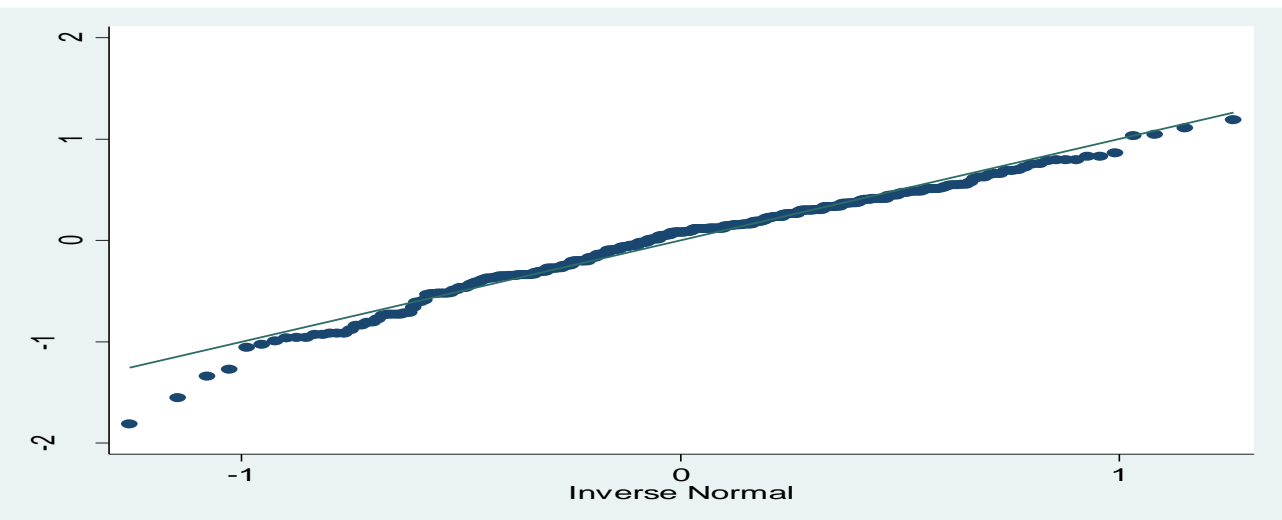

Figura 2 - COM CONTROLE

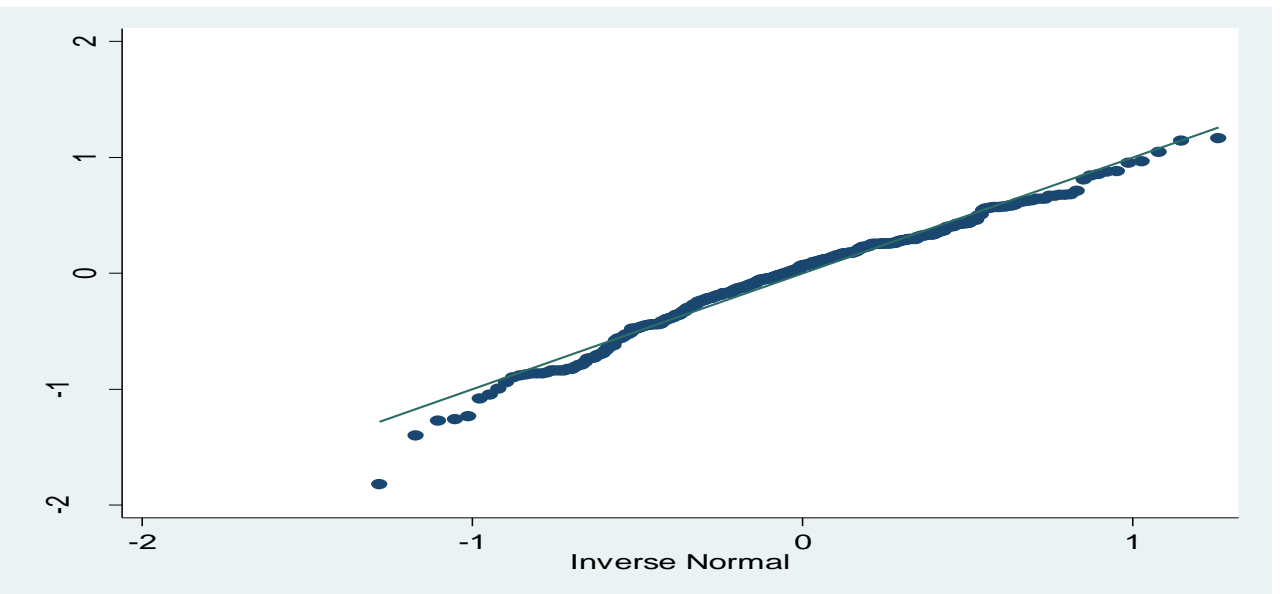

\section{RESULTADOS}

Comparação de Médias Entre os Grupos

O teste de comparação de médias, realizado para comparar as respostas dos alunos das IES privadas com as respostas dos alunos da pública, indicou que não há diferença de opiniões entre os grupos - Tabela 7.

Tabela 7: TESTE DE COMPARAÇÃO DE MÉDIAS DAS IES PÚBLICAS E PRIVADAS

\begin{tabular}{|c|c|c|c|c|c|c|}
\hline \multirow[b]{2}{*}{ Variáveis } & \multicolumn{2}{|c|}{ PÚBLICAS } & \multicolumn{2}{|c|}{ PRIVADAS } & \multicolumn{2}{|c|}{ Diferença de médias } \\
\hline & Média & Desvio Padrão & Média & $\begin{array}{l}\text { Desvio } \\
\text { Padrão }\end{array}$ & $\begin{array}{l}\text { Pública/ } \\
\text { Privada }\end{array}$ & $\mathrm{p}$-value \\
\hline Perfil do egresso (y) & 3.79 & 0.63 & 3.76 & 0.81 & -0.03 & 0.72 \\
\hline Perfil Profissiográfico & 3.83 & 0.71 & 3.78 & 0.90 & -0.04 & 0.63 \\
\hline Perfil Job Description & 3.90 & 0.69 & 3.88 & 0.87 & -0.15 & 0.87 \\
\hline Perfil de Competência & 3.92 & 0.80 & 3.80 & 0.94 & -0.12 & 0.22 \\
\hline Gênero & 0.53 & 0.50 & 0.31 & 0.46 & -0.22 & $0.00 * * *$ \\
\hline Idade & 24.34 & 6.47 & 28.22 & 6.93 & 3.88 & $0.00 * * *$ \\
\hline Renda & 0.95 & 0.96 & 0.63 & 0.77 & -0.32 & $0.00 * * *$ \\
\hline Estágio & 0.63 & 0.48 & 0.50 & 0.50 & -0.13 & $0.02 * *$ \\
\hline Comprometimento & 0.93 & 0.79 & 0.76 & 0.68 & -0.16 & $0.04 * *$ \\
\hline Bolsa Estudantil & 0.03 & 0.17 & 0.10 & 0.10 & -0.02 & 0.15 \\
\hline Trabalho Área Adm. & 0.38 & 0.48 & 0.53 & 0.49 & 0.14 & $0.01 * *$ \\
\hline Tipo de Emprego & 1.40 & 0.89 & 0.69 & 0.90 & -0.70 & $0.00 * * *$ \\
\hline
\end{tabular}

Fonte: Dados da Pesquisa. ** e $\mathrm{e}^{* * *}$ representam coeficientes significativos a $5 \%$ e $1 \%$, respectivamente. 
Analisando os construtos que influenciam, na percepção dos discentes, o desenvolvimento de habilidades e competências pertinentes ao Perfil do egresso, para os dois tipos de instituições, por mais que houvesse diferenças entre os grupos, não houve uma relação estatisticamente significante. Esse resultado pode ser justificado pela padronização do ensino cada vez mais presente. Nela, as IES visado o êxito no ENADE (Exame Nacional de Desempenho de Estudantes), padronizam o ensino conforme os conteúdos da prova, subjulgando aspectos regionais, individuais, institucionais e profissionais que precisam estar presentes na formação do administrador (INEP, 2005; AMATUCCI, 2009; NICOLINI, 2003).

Outro fator que também pode influenciar a avaliação dos alunos - sobretudo aqueles das IES privadas - é o esforço que elas têm despendido para manter suas posições de mercado competitividade - para enfrentar a concorrência. Com isso têm dado mais atenção à qualidade de seus processos, qualificação dos docentes, qualidade da infraestrutura, e tecnologia de ponta; para consolidar sua marca (MUSHTAQ; KHAN, 2012; JULIATTO, 2013).

\section{Análise Fatorial Confirmatória}

Os resultados do p-value das cargas fatoriais, todos estatisticamente significantes, indicam a validade das variáveis explicativas para estimar o modelo - Tabela 8.

Tabela 8 - ANÁLISE FATORIAL CONFIRMATÓRIA

\begin{tabular}{|c|c|c|}
\hline PROFISSIOGRÁFICO & \begin{tabular}{c|} 
Carga \\
Fatorial \\
\end{tabular} & p value \\
\hline Estabeleça sintonia na comunicação com indivíduos ou equipes (comunicação interpessoal). & 1,8635 & 0,000 \\
\hline Desenvolva Raciocínio lógico, crítico e analítico & 2,4032 & 0,000 \\
\hline Compreenda a complexidade administrativa. & 1,9339 & 0,000 \\
\hline $\begin{array}{l}\text { Inove diante das dificuldades das empresas, assumindo as consequências das decisões tomadas } \\
\text { (Gestão Inovadora) }\end{array}$ & 2,7173 & 0,000 \\
\hline Atue com integridade e de maneira consistente, conseguindo se adaptar as mudanças. & 2,0205 & 0,000 \\
\hline Compreenda o cenário do mercado e das empresas para a tomada de decisão. & 1,9391 & 0,000 \\
\hline Compreenda e selecione as estratégias que atendam os objetivos, individual e da equipe. & 3,4060 & 0,000 \\
\hline Compreenda e selecione as estratégias que atendam os objetivos institucionais. & 2,5558 & 0,000 \\
\hline \multicolumn{3}{|l|}{ JOB DESCRIPTION } \\
\hline Entenda, antecipe e procure responder às necessidades do mercado e das empresas & 2,3230 & 0,000 \\
\hline $\begin{array}{l}\text { Possua capacidade de negociação com os fornecedores, clientes, sócios-proprietários, } \\
\text { acionistas... (todos os stakeholders) }\end{array}$ & 2,5511 & 0,000 \\
\hline Compreenda a missão e valores da Organização. & 1,1737 & 0,000 \\
\hline Compreenda as competências essenciais exigidas nos cargos e funções da Organização. & 1,9018 & 0,000 \\
\hline Tenha capacidade técnica e conhecimento. & 2,0882 & 0,000 \\
\hline Tenha ética e moral & 1,1799 & 0,000 \\
\hline Tenha atitude. & 1,0468 & 0,000 \\
\hline Desenvolva habilidade em lidar com diferenças culturais das pessoas. & 1,0982 & 0,000 \\
\hline \multicolumn{3}{|l|}{ COMPETÊNCIA } \\
\hline Possua visão do sistema social-econômico global, para pensar e agir estrategicamente. & 1,7738 & 0,000 \\
\hline Desenvolva capacidade de inovar, para atendimento das necessidades dos clientes. & 2,8800 & 0,000 \\
\hline Possua capacidade de adaptação frente às mudanças. & 1,6698 & 0,000 \\
\hline Possua preocupação com o meio-ambiente e com o desenvolvimento sustentável. & 1,3485 & 0,000 \\
\hline
\end{tabular}

Fonte: Dados da pesquisa. Elaborado pelas autoras 
Regressão Linear Múltipla

Os testes foram executados para identificar quais dos construtos de perfis do administrador (variáveis independentes) seriam estatisticamente significantes para explicar o Perfil do Egresso percebido pelos estudantes (variável dependente). O modelo foi estimado sem variáveis de controle (Painel A), e com variáveis de controle (Painel B) - Tabela 9.

Os resultados do Painel A indicam que para a IES pública, as variáveis independentes do modelo explicam 56\% do Perfil do Egresso; e para as privadas, 64\%. Também indicaram que, para a IES pública, somente as variáveis, Perfil Profissiográfico e Job Description foram estatisticamente significantes para explicar aquele perfil. Para as IES privadas, além do Perfil Profissiográfico e Job Description, a variável Perfil de Competência também foi estatisticamente significante para explicar o Perfil do Egresso.

As estimativas feitas após inclusão das variáveis de controle - Painel B - apresentaram resultados diferentes. Para a IES pública, as variáveis independentes passaram a explicar $60 \%$ do perfil do egresso; e para as privadas, 67\%. Também indicaram que, para a IES pública, somente a variável Perfil Profissiográfico mostrou-se estatisticamente significante para explicar aquele perfil. Para as IES privadas, além do Perfil Profissiográfico, o Job Description, o "trabalho na área administrativa", e o Perfil de Competência se mostraram estatisticamente significante para explicar o perfil do egresso.

Tabela 9: Variáveis que explicam o perfil do egresso do curso de administração

\begin{tabular}{|c|c|c|c|c|}
\hline \multicolumn{5}{|c|}{$\begin{array}{l}\text { Painel A: Resultados da regressão considerando os alunos da IES pública e das privadas, SEM } \\
\text { VARIÁVEIS DE CONTROLE }\end{array}$} \\
\hline & \multicolumn{2}{|c|}{ PÚBLICA } & \multicolumn{2}{|c|}{$\begin{array}{c}\text { PRIVADA } \\
\end{array}$} \\
\hline Variáveis & Coeficiente & p-value & Coeficiente & p-value \\
\hline Constante & 1.05 & $0.00 * * *$ & 0.85 & $0.00 * * *$ \\
\hline Perfil Profissiográfico & 0.28 & $0.00 * * *$ & 0.35 & $0.00 * * *$ \\
\hline Perfil Job Description & 0.28 & $0.01 * *$ & 0.22 & $0.03 * *$ \\
\hline Perfil de Competência & 0.14 & 0.19 & 0.17 & $0.05 * *$ \\
\hline Número de observações & \multicolumn{4}{|r|}{192} \\
\hline $\mathrm{R}^{2}$ & \multicolumn{4}{|c|}{0,56} \\
\hline \multicolumn{5}{|c|}{$\begin{array}{l}\text { Painel B: Resultados da regressão considerando os alunos da IES pública e das privadas, COM } \\
\text { VARIÁVEIS DE CONTROLE }\end{array}$} \\
\hline & \multicolumn{2}{|c|}{$\begin{array}{l}\text { PÚBLICA } \\
\end{array}$} & \multicolumn{2}{|c|}{$\begin{array}{l}\text { PRIVADA } \\
\end{array}$} \\
\hline Variáveis & Coeficiente & $\mathrm{p}$-value & Coeficiente & p-value \\
\hline Constante & 0.97 & $0.00 * * *$ & 0.99 & $0.00 * * *$ \\
\hline Perfil Profissiográfico & 0.26 & $0.02 * *$ & 0.36 & $0.00 * * *$ \\
\hline Perfil Job Description & 0.20 & 0.09 & 0.25 & $0.00 * * *$ \\
\hline Perfil de Competência & 0.19 & 0.14 & 0.15 & 0.07 \\
\hline Gênero & 0.02 & 0.72 & -0.12 & 0.15 \\
\hline Idade & 0.00 & 0.58 & -0.00 & 0.24 \\
\hline Renda & 0.06 & 0.16 & -0.01 & 0.67 \\
\hline Estágio & 0.04 & 0.57 & -0.07 & 0.32 \\
\hline Comprometimento & 0.01 & 0.69 & -0.11 & 0.06 \\
\hline Bolsa Estudantil & -0.06 & 0.75 & -0.97 & 0.22 \\
\hline Trabalho Área Adm. & 0.14 & 0.13 & 0.25 & $0.00 * * *$ \\
\hline Tipo de Emprego & -0.03 & 0.42 & 0.02 & 0.55 \\
\hline Número de observações & & 121 & & 192 \\
\hline $\mathrm{R}^{2}$ & & 0,60 & & 0,67 \\
\hline
\end{tabular}

Fonte: Dados da Pesquisa. ** e $* * *$ representam coeficientes significativos a $5 \%$ e $1 \%$, respectivamente.

Elaborado pelas autoras. 


\section{DISCUSSÃO DOS RESULTADOS}

Os resultados da regressão sem variáveis de controle sugerem que os alunos das IES privadas percebem mais características do perfil do egresso delineado pelo Conselho Federal de Administração do que os da pública: pensar global, analítica e sistemicamente, exercer liderança, saber comunicar-se (Perfil Profissiográfico); ética e profissionalismo (Perfil Job Description); preocupação com o meio ambiente e o desenvolvimento sustentável (Perfil de Competência). As competências para enfrentar as multiplicidades da administração (Perfil Profissiográfico), a visão global e estratégica (Perfil de Competências); atendimento das necessidades mercadológicas que satisfaçam todos os stakeholders (Perfil Job Description); responsabilidade social e sustentável (Perfil de Competências); são fundamentais para a formação de um administrador mais perscrutador, capaz de inter agir no desenvolvimento e transformação do ambiente em que está inserido (SANT'ANNA et al., 2005; ARAÚJO; FARIAS, 2008; MELLO; MELO JR; MATTAR, 2011; CHONG, 2013; MARTINA et al., 2012; SONAGLIO et al., 2013; WEAVER; KULESZA, 2014). O egresso da escola pública só percebe o perfil profissiográfico.

Adicionalmente, ratificam as habilidades mais citadas na literatura - comunicação e habilidades de negociação (Perfil Job Description), habilidades analíticas e habilidades de tomada de decisão (Perfil Profissiográfico), trabalho em equipe e o relacionamento interpessoal (Perfil Profissiográfico) - que as considera como o conjunto de competências basilares para o enfrentamento do volátil ambiente de negócios (MATHER et al., 2011; HANSON, 2010; MARTINA et al., 2012; SENGE et al., 2012; SONAGLIO et al., 2013; WEAVER; KULESZA, 2014).

No Painel B da Tabela 9 - estimativa com variáveis de controle - notou-se uma melhoria na capacidade de explicação do modelo, $60 \%$ e $67 \%$, respectivamente, para IES pública e privadas. Mas, por outro lado, o retirou o perfil de competência como explicativo para o perfil do egresso percebido pelos estudantes das IES privadas; e mostrou que o "trabalhar na área" é significativo para os estudantes perceberem perfil esperado do administrador. Esse resultado sugere que a experiência profissional é considerada pelos estudantes como necessária para formar o perfil esperado pelo mercado de trabalho. Ou seja, ela interage com a formação acadêmica desenvolvendo as competências que definirão o perfil do egresso para o mercado. Conforme defendeu Cruz (2012) a prática se torna mais consistente quanto mais substancial for a teoria; e Mintzberg (2006) que a experiência é a base para a observação e reflexão, e ambas essenciais para a preparação do egresso.

Cabe também ressaltar o fato de a variável Perfil de Competência não ter se mostrado estatisticamente significante para explicar o perfil do egresso da IES pública; e na Privada, ter se mostrado significante somente ao nível de $10 \%$ de confiança. Esse resultado suscita atenção porque o Perfil de Competência inclui a preocupação com o meio ambiente e o desenvolvimento sustentável. Segundo Brunstein, Heidrich e Amaro (2016) os alunos possuem mais comprometimento cívico e habilidades em lidar com as diferenças culturais quando são despertados em relação à consciência da responsabilidade e sustentabilidade social e ambiental (MATHER et al., 2011).

\section{CONCLUSÕES}

Este artigo se propôs a preencher a lacuna da literatura sobre perfil dos profissionais de Administração pesquisando a percepção dos estudantes sobre as competências que estão sendo desenvolvidas durante suas formações acadêmico-profissionais. As estatísticas descritivas 
sugeriram que alguns deles tendem a concordar que sim, mas há outros que não - já que os desvios-padrão das médias dos construtos apontaram dispersão entre as opiniões.

O seu objetivo foi o de apontar as competências que os estudantes de Administração percebem que lhes foram desenvolvidas durante o curso. Os resultados apontaram que os alunos da IES pública percebem que somente o Perfil Profissiográfico está sendo desenvolvido; enquanto os alunos das IES privadas percebem, além do Profissiográfico, o Job Description e o Perfil Competência (somente ao nível de significância de 10\%).

A não significância estatística da variável Perfil de Competência, ao nível de 5\% de confiança, pode ser justificada: (i) pela possibilidade de que as habilidades e competências desse construto ainda não tivessem sido devidamente trabalhadas com os alunos quando responderam os questionários desta pesquisa, impedindo-os de perceber o seu efeito sobre sua preparação o mercado de trabalho; (ii) não estar havendo um trabalho adequado para desenvolver essas habilidades e competências; e/ou (iii) os alunos não estão percebendo esse aprendizado. Todas possibilidades suscitam falhas no processo de ensino da IES, e refletem a problemática que perpassa a discussão deste estudo que é a qualidade do ensino superior em Administração, e em que medida a ela reflete no perfil do egresso.

Essa perspectiva de análise pode ser relevante para as IES na medida em que aponta aspectos que estão relacionados com a qualidade dos cursos, que são muito importantes para os agentes educacionais, por estarem submetidos a avaliações periódicas de seus cursos através dos exames do ENADE; e para os discentes, porque as deficiências em suas formações repercutem de forma negativa em suas empregabilidades.

Ela traz como contribuição para a literatura o fato de ter abordado especificamente as variáveis contidas na regulamentação dos cursos de Administração e na perspectiva das competências, oferecendo base comparativa para a análise da evolução desses cursos. Contudo, tem limitações: a natureza não probabilística da amostra - que não permite generalizar os resultados; não ter abrangido todas as competências e habilidade necessárias para a formação do Administrador - devido à complexidade da profissão que acolhe uma grande quantidade de competências e habilidades. Assim, sugere-se como pesquisas futuras a ampliação do campo de estudo para um número maior de IES com inclusão de mais competências e habilidades do Administrador.

\section{REFERÊNCIAS}

AMATUCCI, M. Método para a construção do perfil de competências do egresso de curso de Administração. Revista Administração em Diálogo, v. 12, n. 1, p. 89 - 108. 2009.

ARAÚJO, F. R. de S.; FARIAS, O. B. Ramos de. Proposta de um modelo pedagógico para o curso de graduação em administração: uma discussão à luz da interdisciplinaridade. Revista Gestão Organizacional, Ed. Especial, p. 1-13, 2008.

ARAÚJO, G. D. et al. Currículo e vínculos teoria-prática: reflexões no processo ensinoaprendizagem em um curso de graduação em Administração. Revista de Gestão do Unilasalle, v. 3, n. 2, p. 09-31, 2014.

BRANDÃO, H. P.; BORGES-ANDRADE, J. E. Causas e efeitos da expressão de competências no trabalho: para entender melhor a noção de competência. Revista de Administração Mackenzie, v. 8, n. 3, p 32-49, 2008. 
BRASIL. Resolução CNE/CES Nº 04, de 13 de julho de 2005. Institui as Diretrizes Curriculares Nacionais para o Curso de Graduação em Administração, bacharelado, e dá outras providências. Diário Oficial [da] República Federativa do Brasil. Brasília (DF): Senado Federal, 13 jul. 2005. Disponível em: <http://portal.mec.gov.br/cne/arquivos/pdf/rces004_05.pdf>. Acesso em: 14 jun. 2016.

BRITTO, L. P. L. et al. Conhecimento e formação nas IES periféricas: perfil do aluno" novo" da educação superior. Avaliação, Campinas, v. 13, n. 3, 2008.

BRUNSTEIN, J.; HEIDRICH, S. B.; AMARO, R. A. Competências para o fair play nas organizações: uma análise fenomenográfica das concepções dos gestores. Brazilian BusinessReview, (Port. ed., Online), v. 13, n. 2, p. 109 - 140, mar./abr. 2016.

BURNIER, S. Pedagogia das competências: conteúdos e métodos. Boletim técnico do Senac, v. 27, n. 3, p. 49-60, 2001.

CHING, H. Y.; SILVA, E. C.; TRENTIN, P. H. Formação por competência: experiência na estruturação do projeto pedagógico de um curso de Administração. Administração: Ensino e Pesquisa, v. 15, n. 4, p. 697-727, 2014.

CHONG, E. Managerial competencies and career advancement: A comparative study of managers in two countries. Journal of Business Research, v. 66, n. 3, p. 345-353, 2013.

CRUZ, G. B. Teoria e prática no curso de pedagogia. Educação e Pesquisa, São Paulo, v. 38, n. 1 , p. $149-164,2012$.

ECHEVESTE, S. et al. Perfil do Executivo no Mercado Globalizado. Revista Administração Contemporânea, v. 3, n. 2, p. 167-186. Mai./Ago. 1999.

GODEMANN, J. et al. Integrating sustainability into business schools-Analysis of $100 \mathrm{UN}$ PRME Sharing Information on Progress (SIP) reports. Nottingham: International Centre for Corporate Social Responsibility, n. 58, 2011.

HAAN, G. The BLK '21'programme in Germany: a 'Gestaltungskompetenz'-based model for education for sustainable development. Environmental Education Research, v. 12, n. 1, p. 19-32, 2006.

HANSON, K. R. Action learning strategies on continuous improvement efforts in elementary schools. University of La Verne, 2010.

HOCAYEN-DA-SILVA, A. J.; DE CASTRO, M.; MACIEL, C. de O. Perfil profissional e práticas de docência nos cursos de Administração: por onde andam as novas tecnologias do ensino superior? Revista de Administração Mackenzie, v. 9, n. 5, 2008.

IBGE. Instituto Brasileiro de Geografia e Estatística. 2016. Disponível em: $<$ http://www.ibge.gov.br/apps/snig/v1/?loc $=0 \&$ cat=2,-2,-13,128\&ind=4699>. Acesso em: 15 jul. 2016. 
IIZUKA, E. S.; DE MORAES, G.H. S. M. Análise do potencial e perfil empreendedor do estudante de administração e o ambiente universitário: reflexões para instituições de ensino. Administração: Ensino e Pesquisa, Rio de Janeiro, v. 15, n. 3, p. 593-630, 2014.

INEP. Instituto Nacional de Estudos e Pesquisas Educacionais Anísio Teixeira. Censo da educação superior: resultados e tendências. 2013. Disponível em: <http://download.inep.gov.br/download/superior/censo/2013/resumo_tecnico_censo_educaca o_superior_2013.pdf>. Acesso em: 01 jun. 2016.

KARAWEJCZYK, T. C.; ESTIVALETE, V. de F.B. O sentido do trabalho e o desenvolvimento de competências: perspectivas sob a ótica do professor universitário. Anais...Encontro de Estudos Organizacionais, v. 2, 2002.

KERZNER, H. Project management: a systems approach to planning, scheduling, and controlling. New York: John Wiley \& Sons, 2013.

MARQUARDT, M.; WADDILL, D. The power of learning in action learning: a conceptual analysis of how the five schools of adult learning theories are incorporated within the practice of action learning. Action Learning: Research and Practice, v. 1, n. 2, p. 185-202, 2004.

MARTINA, K.; HANA, U.; JIRI, F. Identification of managerial competencies in knowledgebased organizations. Journal of competitiveness, v. 4, n. 1, 2012.

MATHER, G. et al. Business graduate skills in sustainability. Journal of Global Responsibility, v. 2, n. 2, p. 188-205, 2011.

MELLO, Sebastião Luiz de; MELO JR, José Samuel de Miranda; MATTAR, Fauze Najib (orgs). Perfil, formação, atuação e oportunidades de trabalho do administrador: pesquisa nacional. 5. ed. Brasília: CFA, 2011. Disponível em http://www.cfa.org.br/servicos/publicacoes/pesquisa-perfil-2011.pdf

MINTZBERG, Henry. MBA? Não obrigado: uma visão crítica sobre a gestão e desenvolvimento de gerentes. Porto Alegre: Bookman, 2006.

MOTTA, Fernando Claudio Prestes. A questão da Formação do Administrador. Revista Administração de Empresas. 23 (4). p. 53-55. 1983.

MOURA, M. C. C. de; BITENCOURT, C. C. A articulação entre estratégia e o desenvolvimento de competências gerenciais. RAE- Eletrônica, v. 5, n. 1, jan/jun. 2006.

MOURA, J. G. de; MOURA, E. P. Finanças públicas e eficiência privada no Estado do Maranhão. Revista Políticas Públicas, v. 5, n. 1-2, 2015.

MUSHTAQ, I.; KHAN, S. N. Factors affecting students' academic performance. Global Journal of Management and Business Research, v. 12, n. 9, 2012. 
NASSIF, V. M. J.; HANASHIRO, D. M. M. A competitividade das universidades particulares à luz de uma visão baseada em recursos. Revista de Administração Mackenzie, v. 3, n. 1, 2008.

NICOLINI, A. Qual será o futuro das fábricas de administradores? RAE, v. 43, n. 2, p. 44-54, abr./jun. 2003.

PATAH, L. A.; CARVALHO, M. M. de. Alinhamento entre estrutura organizacional de projetos e estratégia de manufatura: uma análise comparativa de múltiplos casos. Gest. Prod, v. 16, n. 2, p. 301-312. 2009.

PELECKIS, K.; PELECKIENE, V. Developing negotiation competencies of business management students: structural and content dimensions. Business: Theory and Practice, v. 14, n. 4, p. 346-357, 2013.

PERIN, M. et al., O impacto da formação gerencial no desempenho organizacional à luz da abordagem de competências. BBR - Brazilian Business Review. v. 6, n.1, pp 104-120, 2009.

PESSOA, E. D.; MARTINS, M. A dinâmica econômica e condições de vida da população Maranhense no período de 1970-90. Revista Políticas Públicas, v. 2, n. 2, 2015.

PFEFFER, J.; FONG, C. T. Educação em administração. O fim das escolas de negócio? RAERevista de Administração de Empresas, v. 43, n. 2, p. 11-28, 2003.

PINTO, M. R. et al. A construção de significados ao curso de graduação em Administração pelos alunos de alta e de baixa renda. BBR- Brazilian Business Review. v. 12, n. 4, p. 84-104, jul./ago. 2015.

PIZZINATTO, N. K. Ensino de administração e o perfil do administrador: contexto nacional e o curso de administração da Unimep. Revista Impulso, v. 11, n. 26, p. 173-190, 1999.

RIBEIRO, C. V. dos S.; MANCEBO, D. O servidor público no mundo do trabalho do século XXI. Psicologia: Ciência e Profissão, v. 33, n. 1, p. 192-207, 2013.

ROCHA-DE-OLIVEIRA, S.; PICCININI, V. C. Uma análise sobre a inserção profissional de estudantes de Administração no Brasil. Revista de Administração Mackenzie, v. 13, n. 2, p. 44-75, 2011.

SANT'ANNA, A. de S.; DE MORAES, L.F. R.; KILIMNIK, Z. M. Competências individuais, modernidade organizacional e satisfação no trabalho: um estudo de diagnóstico comparativo. RAE-eletrônica, v. 4, n. 1, p. 1-23, 2005.

SENGE, P. et al. Schools that learn: a fifth discipline fieldbook for educators, parents, and everyone who cares about education. New York: Crown Publishing Group. 2012.

SILVA, E. R. Reflexões sobre o ensino de Administração no Brasil. Revista de Administração da Fatea, v. 5, n. 5, p. 60-73, jan./dez., 2012. 
SONAGLIO, A. L. B.; GODOI, C. K.; SILVA, A. B. da. Estilos de aprendizagem experiencial e aquisição de habilidades: um estudo com discentes de graduação em administração em instituições de ensino superior. Administração: Ensino e Pesquisa. v. 14, n. 1, p. 123-159. Rio de Janeiro. 2013.

VIEIRA, A.; LUZ, T. R. Do saber aos saberes, comparando as noções de qualificação e de competência. O\&S, v. 12, n. 33. 2005.

WEAVER, P.; KULESZA, M. Critical skills for new accounting hires: what's missing from traditional college education? Academy of Business Research Journal, v. 4, p. 34-49, 2014.

WEISE, A. D. et al. Análise comparativa dos cursos de graduação em Administração na Alemanha, no Brasil e nos Estados Unidos da América. Rev. Adm. UFSM, v. 7, n. 2, p. 279$295,2014$.

WRIGHT, J. T.C.; SILVA, A. T. B.; SPERS, R. G. O mercado de trabalho no futuro: uma discussão sobre profissões inovadoras, empreendedorismo e tendências para 2020. Revista de Administração e Inovação, v. 7, n. 3, p. 174-197, 2010. 